\section{Predictor factor of inguinal lymph lode metastasis in men with penile cancer at Sanglah General Hospital, Denpasar, Bali}

\author{
I. Wayan Yudiana, ${ }^{1}$ \\ Gede Wirya Kusuma Duarsa, ${ }^{1}$ \\ Anak Agung Gde Oka, ${ }^{1}$ \\ Kadek Budi Santosa, ${ }^{1}$ \\ Pande Wisnu Tirtayasa, ${ }^{1}$ Harmaya AK, ${ }^{2}$ \\ Wahjoe Djatisoesanto ${ }^{2}$ \\ ${ }^{1}$ Department of Urology, Faculty of \\ Medicine, Udayana University/Sanglah \\ General Hospital, Denpasar, Bali; \\ ${ }^{2}$ Department of Urology, Faculty of \\ Medicine, Airlangga University/Soetomo \\ Hospital, Surabaya, Indonesia
}

\begin{abstract}
Background: To know predictor factors of inguinal node metastasis in penile cancer.

Methods: A retrospective study about penile cancer in Sanglah Hospital, Bali, from 2011 to 2015. Patients had undergone partial or total penectomy, and inguinal node dissection or excisional biopsy for histopathology finding. Results: A 65 penile cancer patients were diagnosed for 5 years. Mean age was 53,24 $\pm 13,42$ years. Fifteen were excluded and 25 of 50 patients $(50 \%)$ had inguinal node metastasis. There were significant correlation between pathologic stage $(p=0,021)$, histologic grade $(p=0,020)$ and vascular invasion $(\mathrm{p}=0,008)$ with the presence of inguinal node metastasis. Primary tumor of $\mathrm{pT} 1$ showed $14 \%$ inguinal node metastasis compared to pT2 (42\%), pT3 (67\%), and pT4 (100\%). Histologic grade I, had $22 \%$ inguinal node metastasis compared to grade II $(50 \%)$, and grade III $(100 \%)$. Only $39 \%$ patients without vascular invasion had inguinal node metastasis compared to $83 \%$ with vascular invasion.

Conclusion: Pathologic stage of primary tumor, histologic grade and vascular invasion were predictor factors of inguinal node metastasis in penile cancer.
\end{abstract}

\section{Introduction}

Penile cancer is a rare but potentially fatal malignancy. Its causes are not entirely understood, but the risk is almost completely eliminated by circumcision at birth. The incidence is higher in Africa, India, China, and parts of South America than it is in most Western countries, including the United States. Squamous cell carcinoma of the penis was found to be $43 \%$ greater in men from countries where the poverty level is $>20 \% .^{1}$ There are a few randomized trials exploring treatment options for penile cancer, but due to the small numbers of patients, management is typically based on retrospective reviews from large referral centers. Consequently, guidelines for treatment, such as those recently published by the European Association of Urology, are based on low-grade recommendations. ${ }^{2}$

The gold standard treatment for primary penile lesions remains to be total or partial penectomy. This standard therapy of total/partial penectomy for penile cancer achieves local control rates above $90 \%$ but also causes significant disfiguration, leading to loss of function and psychosexual morbidity. ${ }^{3}$ If there are no palpable lymph nodes, the likelihood of micrometastatic disease is about 25\%. ${ }^{4}$ Inguinal lymphadenopathy by physical examination exhibits low positive and negative predictive values. In one report of 100 men with penile cancer treated according to the European Association of Urology (EAU) guidelines in a single institution, $72 \%$ of men with palpable lymph nodes (LNs) and $18 \%$ with impalpable LNs had pathological LN involvement. ${ }^{5}$ Controversies surround the role and extent of immediate inguinal lymphadenectomy with or without sentinel LN dissection in those without clinical lymphadenopathy, as well as the role of pelvic LN dissection. In a large surgical series of 688 patients, immediate lymphadenectomy $(n=251)$ was associated with a better 10year disease-specific survival than delayed $(\mathrm{n}=81)$ lymphadenectomy $(71 \%$ vs. $30 \%$, $\mathrm{p}=0.002$ ). The 10 -year disease-free survival rates for patients with negative and positive pathological nodal involvement in the immediate lymphadenectomy group were $96 \%$ and $35 \%$, respectively. ${ }^{6}$ Proper diagnostic and treatment, particularly regarding inguinal lymph node metastasis, will affect the prognosis. That is why we need to know the predictor factor of inguinal lymph node metastasis in men with penile cancer. In this study, predictor factors that will be examined include pathologic stage of the primary tumor, histologic grade, vascular invasion and age of patient.

\section{Objective}

To know the predictor factor of inguinal lymph node metastasis in men with penile cancer.

\section{Materials and Methods}

This study was an analytic retrospective study. The samples in this study were
Correspondence: Gede Wirya Kusuma Duarsa, Departement of Urology, Faculty of Medicine, Udayana University/Sanglah General Hospital, Jln. Kesehatan No.1 Denpasar, Bali, Indonesia.

Tel.: +628155753377

E-mail: gwkduarsa@gmail.com

Key words: tumor staging, tumor grading, vascular invasion, inguinal metastasis, penile cancer

Contributions: All the authors contributed equally.

Conflict of interest: The authors declare no potential conflict of interest.

Received for publication: 1 February 2019. Accepted for publication: 12 February 2019.

This work is licensed under a Creative Commons Attribution-NonCommercial 4.0 International License (CC BY-NC 4.0).

CCopyright I.W. Yudiana et al., 2019

Licensee PAGEPress, Italy

Dermatology Reports 2019; 11(s1):8046 doi:10.4081/dr.2019.8046

patients diagnosed as penile cancer in Sanglah General Hospital, Denpasar Bali from January 2011 to December 2015. Data obtained through medical records with penile cancer as the primary diagnosis.

Inclusion criteria include patients with penile cancer, which was confirmed by the pathological result, underwent partial or total penectomy for the primary tumor, and underwent dissection or excisional biopsy for inguinal lymph node. Exclusion criteria include patients who did not undergo partial or total penectomy, and patients who did not undergo inguinal lymph node dissection or excisional biopsy.

Penile cancer patient treated at Sanglah General Hospital, Denpasar Bali that meet the inclusion and exclusion criteria will be included as a sample in this study. Patients with penile cancer will be recorded regarding age, address, TNM staging and procedures given (surgery, chemotherapy and radiotherapy). For ratio data, it will be displayed in the form of average and standard deviation. For the nominal and ordinal data, the data will be displayed as a percentage. For nominal and ordinal data, the data analyzed using Chi Square and Kruskal-Wallis test to know the correlation between pathologic stage of the primary tumor, histologic grade, vascular invasion and age with the presence of inguinal lymph node metastasis. The data was processed and analyzed using SPSS 17.0 for Windows computer software. 


\section{Results}

A total of 65 patients diagnosed as penile cancer in Sanglah General Hospital, Denpasar Bali from 2011 to 2015. Mean age of these patients was 53,24 $\pm 13,42$ years. The youngest age was 27 years old and the oldest was 86 years old. The samples that met the inclusion criteria was as much as 50 patients. Therapy for the primary tumor was done on 58 patients, in the form of a partial penectomy in $21(36 \%)$ patients and total penectomy in $37(64 \%)$ patients. Two patients did not undergo therapy for primary tumors because they died before therapy, and 5 patients lost of follow up after penile biopsy was performed. Therapy for the inguinal lymph node was done on 50 patients, such as inguinal lymph node dissection in 33 patients and inguinal lymph node excisional biopsy in 17 patients. Eight patients who underwent therapy for the primary tumor, but did not undergo inguinal lymph node dissection or excisional biopsy because they did not have inguinal lymphadenopathy. Characteristics of the patients can be seen in Table 1. Most of penile cancer in staging $\geq \mathrm{T} 2$ were underwent total penectomy (33 cases). Partial penectomy for penile cancer with staging $\geq \mathrm{T} 2$ were only performed in 15 cases. All of penile cancer in staging T4 were underwent total penectomy. In this study, penile cancer most commonly affects men between the ages of 40-49 years, with only $2 \%$ at ages $<30$ years. There was no significant relationship between age and inguinal lymph node metastasis $(p=0,829)$ (Table 2$)$. Based on pathologic stage of the primary tumor (Figure 1), only 1 of 7 patients (14\%) with pT1 had inguinal lymph node metastasis compared with 10 of 24 patients ( $42 \%$ ) with pT2, 10 of 15 patients (67\%) with pT3, and 4 of 4 patients with pT4 (100\%). There was a significant correlation between pathologic stage of the primary tumor and inguinal lymph node metastasis $(p=0.021)$. Patients with higher pathologic stage had higher risk to have an inguinal lymph node metastasis.

Based on histologic grade, only 2 of 9 patients $(22 \%)$ with grade I had inguinal lymph node metastasis compared with 18 of 36 patients $(50 \%)$ with grade II, and 5 of 5 patients $(100 \%)$ with grade III. There was a significant correlation between histologic grade and inguinal lymph node metastasis $(p=0.020)$, in which higher histologic grade had a higher risk to have an inguinal lymph node metastasis.

Based on vascular invasion, only 15 of 38 patients (39\%) without vascular invasion had inguinal lymph node metastasis compared with 10 of 12 patients $(83 \%)$ with vascular invasion. There was a significant correlation between vascular invasion and inguinal lymph node metastasis $(\mathrm{p}=0.008)$, in which patients with vascular invasion had a higher risk to have an inguinal lymph node metastasis.

\section{Discussion}

In the USA, penile cancer most commonly affects men between the ages of 50 70 years, with only $19 \%$ at ages $<40$ years and $7 \%<30$ years. ${ }^{1}$ Squamous cell carcino-

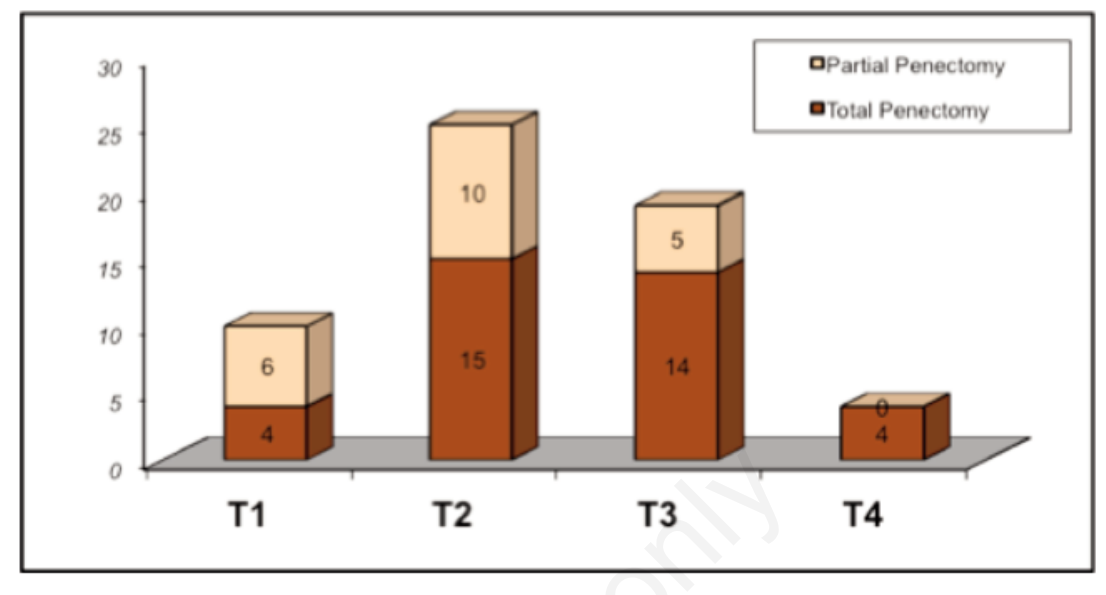

Figure 1. Pathologic stage and treatment for primary tumor.

Table 1. Patient characteristic.

$\begin{array}{lccccc}\text { Variable } & \text { Frequency } & (\%) & \text { Min } & \text { Max } & \text { Mean } \\ \text { Age (years old) } & & 27 & 86 & 53,24+13,42\end{array}$

Clinical staging:

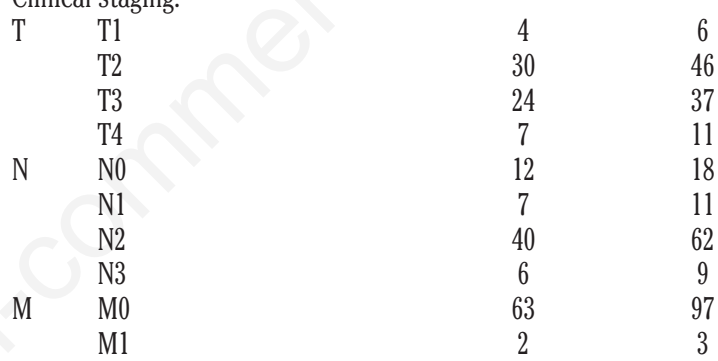

\begin{tabular}{lll} 
Treat for primary tumor: & & \\
Partial penektomy & 21 & 36 \\
Total penektomy & 37 & 64 \\
\hline
\end{tabular}

Treat for ILN:

Right ILND $\quad 1 \quad 2$

Left ILND

Bilateral ILND

Right ILN biopsy

Left ILN biopsy

Bilateral ILN biopsy

6

7

1

2

\begin{tabular}{lcc} 
Histologic grading: & & \\
I & 10 & 17 \\
II & 40 & 69 \\
III & 8 & 14 \\
\hline
\end{tabular}

Limfo-vascular invasi:

$\begin{array}{lll}\text { Yes } & 13 & 22 \\ \text { None } & 45 & 78\end{array}$

Histologic type:

Usual SCC

Condylomatous SCC $\quad 58 \quad 90$

$\begin{array}{lll}\text { Papillary SCC } & 5 & 3\end{array}$

ILN: inguinal lymp node; ILND : inguinal lymp node dissection. SCC: squamous cell carcinoma. 
ma of the penis in younger patients was more likely to exhibit infiltrative growth pattern, perineural invasion, and recurrence. ${ }^{7}$ In Indonesia, the research conducted at Sardjito Hospital from 2006 to 2013 found 35 cases of penile cancer, in which most commonly affects men between the ages of $40-60$ years $(45.7 \%) .{ }^{8}$ Another study done at Cipto Mangunkusumo Hospital and Dharmais Cancer Hospital from October 1994 to September 2005 found 69 cases of penile cancer, in which most commonly affects men between the ages of 40-50 years old. ${ }^{9}$

In this study, among 65 penile cancer patients from 2011 to 2015 , most commonly affects men between the ages of 40-49 years, with only $12 \%$ at ages $<40$ years. There was one $(2 \%)$ penile cancer patient aged $<30$ years old and already had inguinal lymph node metastasis. There was no significant relationship between age and inguinal lymph node metastasis $(\mathrm{p}=0,829)$.

The World Health Organization (WHO) classifies penile SCC, or penile cancer, as usual, basaloid, verrucous, warty (condylomatous), papillary, sarcomatoid, adenosquamous and mixed. In a surgical series of 333 patients receiving homogeneous surgery, basaloid, sarcomatoid and adenosquamous carcinomas displayed the highest histological grade and deep tissue infiltration, while verrucous, papillary and condylomatous (warty) carcinomas were associated with low grade and superficial invasion. This relationship translated into distinct clinical behavior, with a higher 10year survival rate for verrucous, adenosquamous, mixed, papillary and warty carcinoma $(100 \%, 100 \%, 97 \%, 92 \%$ and $90 \%$, respectively), while patients with the usual and basaloid types had $78 \%$ and $76 \% 10$ year survival, respectively. ${ }^{10}$ In this study, $90 \%$ of squamous cell carcinoma are usual type, $7 \%$ were condylomatous type and $3 \%$ were papillary type. Of the 5 patients with condylomatous type, 4 of them were T2 and the rest were $\mathrm{T} 1$.

A partial and glans-sparing penectomy provides psychosocial benefits, preserves sexual function and is generally feasible for a T1 tumor. A 2-cm margin has been advocated historically, although some recent data suggest a 5- to $10-\mathrm{mm}$ margin may be adequate. $^{3}$ Total penectomy is preferred for $\geq \mathrm{T} 2$ tumors, although some $\mathrm{T} 2$ tumors are amenable to partial penectomy based on location. In Sanglah General Hospital, total penectomy (33 cases) was mostly done to penile cancer with $\geq \mathrm{T} 2$ tumor. Partial penectomy for penile cancer with $\geq \mathrm{T} 2$ was only performed in 15 cases. This was because penile cancer has spread to more proximal part of the penis, so it does not

Table 2. The predictor factors of inguinal lymph node metastasis in men with penile cancer.

\begin{tabular}{|c|c|c|c|c|}
\hline Variable Age (yo) & $N-(\%)$ & $N+(\%)$ & & p value* \\
\hline$<30$ & $0(0)$ & $1(2)$ & & 0,829 \\
\hline $30-39$ & $4(8)$ & $3(6)$ & & \\
\hline $40-49$ & $7(14)$ & $10(20)$ & & \\
\hline $50-59$ & $6(12)$ & $5(10)$ & & \\
\hline $60-69$ & $6(12)$ & $5(10)$ & & \\
\hline$>70$ & $2(4)$ & $1(2)$ & & \\
\hline Variable (p'T) & $N-(\%)$ & $N+(\%)$ & Total (\%) & p value* \\
\hline $\mathrm{T} 1$ & $6(12)$ & $1(2)$ & $7(14)$ & 0,021 \\
\hline T2 & $14(28)$ & $10(20)$ & $24(48)$ & \\
\hline $\mathrm{T} 3$ & $5(10)$ & $10(20)$ & $15(30)$ & \\
\hline T4 & $0(0)$ & $4(8)$ & $4(8)$ & \\
\hline Total (\%) & $25(50)$ & $25(50)$ & $50(100)$ & \\
\hline Variable (Grading) & $N-(\%)$ & $N+(\%)$ & Total (\%) & p value ${ }^{* *}$ \\
\hline I & $7(14)$ & $2(4)$ & $9(18)$ & 0,02 \\
\hline II & $18(36)$ & $18(36)$ & $36(72)$ & \\
\hline III & $0(0)$ & $5(10)$ & $5(10)$ & \\
\hline Total (\%) & $25(50)$ & $25(50)$ & $50(100)$ & \\
\hline Variable (LVI) & N- $(\%)$ & $\mathrm{N}+(\%)$ & Total (\%) & p value ${ }^{* *}$ \\
\hline Yes & $2(4)$ & $10(20)$ & $12(24)$ & 0,008 \\
\hline None & $23(46)$ & $15(30)$ & $38(76)$ & \\
\hline Total (\%) & $25(50)$ & $25(50)$ & $50(100)$ & \\
\hline
\end{tabular}

*Kruskal-Wallis test; **Chi-square test. LVI: limfo-vascular invasi. qualify for partial penectomy.

In this study, there was significant correlation between pathologic tumor stage and inguinal lymph node metastasis $(\mathrm{p}=0,021)$. The risk of inguinal lymph node metastasis increased with increase in pathologic tumor stage. Based on pathologic stage of the primary tumor, only 1 of 7 patients $(14 \%)$ with pT1 had inguinal lymph node metastasis compared with 10 of 24 patients (42\%) with pT2, 10 of 15 patients $(67 \%)$ with pT3, and 4 of 4 patients with pT4 (100\%). Slaton et al. reported that pathological tumor stage was the predictor of nodal metastasis in penile cancer. None of 15 pT1 tumors exhibited vascular invasion or lymph node metastasis. Of 33 patients with pT2 or greater tumors 21 (64\%) had vascular invasion and 18 (55\%) had metastasis. ${ }^{11}$ Dai et al. reported that the rate of lymph node metastasis was $18.8 \%$ in patients with pT1, as compared with $53.1 \%$ in patients with pT2 or pT3 $(\mathrm{p}=0.004) .{ }^{12}$

Vascular invasion was also known as the predictor of nodal metastasis in penile cancer. In this study, there was significant correlation between vascular invasion and inguinal lymph node metastases $(p=0.008)$. Patient with vascular invasion had higher risk of the presence of inguinal lymph node metastasis. Only 15 of 38 patients (39\%) without vascular invasion had inguinal lymph node metastasis compared with 10 of 12 patients $(83 \%)$ with vascular invasion. This was similar with the result of study conducted by Slaton et al. Of 33 patients with pT2 or greater tumors $21(64 \%)$ had vascular invasion and 18 (55\%) had metastasis. ${ }^{13}$ Emerson et al. reported that vascular invasion was strongly associated with cancer progression risk. All patients with vascular invasion developed metastasis while metastatic disease was observed in only a minority lacking vascular invasion. ${ }^{13}$

This study also found a significant correlation between histologic grade and inguinal lymph node metastasis $(\mathrm{p}=0,020)$. The risk of inguinal lymph node metastasis increased with increase in histologic grade. Inguinal lymph node metastasis were found in 2 of 9 grade $1(22 \%), 18$ of 36 grade 2 $(50 \%)$, and 5 of 5 grade 3 carcinomas $(100 \%)$. Slaton et al. reported that presence of greater than $50 \%$ poorly differentiated cancer was the predictor of nodal metastasis in penile cancer. Only 4 of 25 patients (15\%) with $50 \%$ or less poorly differentiated cancer in the penile tumor had metastasis compared with 14 of 23 patients $(61 \%)$ with greater than $50 \%$ poorly differentiated cancer $(p=0.001) .{ }^{11}$ Velazquez et al. reported that high histologic grade was statistically significant pathologic factors associated with inguinal lymph node metastasis. Nodal 
metastasis were found in 2 of 25 grade 1 ( $8 \%), 24$ of 46 grade $2(52 \%)$, and 40 of 63 grade 3 carcinomas $(63 \%)(p=0.0001) .{ }^{14}$

Ramkumar et al. reported that histologic grade of the primary tumor was found to be the only significant factor predicting development of regional node metastasis in clinically node-negative penile cancer patients. From 200 clinically node-negative penile cancer patients who were kept under surveillance after treatment of the primary tumor, lymph node metastasis occurred in 31 patients at a median time of three months. Histologic grade 3 and grade 2 tumors had a statistically significant increased odds ratio for lymph node metastasis, $(7.1[\mathrm{P}<0.001]$ and $2.7[\mathrm{p}=0.04]$, respectively), compared with grade 1 tumors. Patients with grade 3 and grade 2 tumors may benefit from elective inguinal lymphadenectomy. ${ }^{15}$ With uni- or bilateral palpable inguinal lymph nodes $(\mathrm{cN} 1 / \mathrm{cN} 2)$, metastatic lymph node disease is very likely and the traditional clinical advice to prescribe antibiotic treatment to exclude lymph node enlargement due to infection is no longer correct. Instead, appropriate oncological diagnosis and treatment should be undertaken without delay before further metastatic spread occurs. In clinically doubtful cases, US-guided fine needle aspiration cytology can be an option. ${ }^{4}$ For lowrisk compliant patients (pTis, pTa and pT1G1) without palpable LNs, surveillance was recommended. For all other patients without palpable LNs, a modified bilateral lymphadenectomy or sentinel LN dissection was recommended. Radical inguinal lymphadenectomy was recommended for patients with histologically proven LN metastasis. In addition, pelvic LN dissection was recommended in patients with multiple inguinal LNs, extranodal extension or node of Cloquet involvement. ${ }^{10}$

The weakness of this study was the incomplete data obtained through medical records. The data was limited to the identity of the patient, therapy for the primary tumor and inguinal lymph node, and the results of histopathology. Additional therapeutic modalities (such as chemotherapy and radiotherapy) and follow-up of patients were not recorded properly.

\section{Conclusions}

A total of 65 patients diagnosed as penile cancer in Sanglah Hospital, Denpasar Bali, Indonesia from January 2011 to December 2015. Mean age of these patients was 53,24 $\pm 13,42$ years. Pathologic stage of the primary tumor, histologic grade and vascular invasion were predictor factor of inguinal lymph node metastasis in men with penile cancer, while age of patient was not associated with the presence of inguinal lymph node metastases.

\section{References}

1. Pow-Sang MR, Ferreira U, Pow-Sang JM, et al. Epidemiology and natural history of penile cancer. Urology 2010;76:S2-S6.

2. Moses KA, Winer A, Sfakianos JP, et al. Contemporary management of penile cancer: Greater than 15-year MSKCC experience. Can J Urol 2014;21:72017206.

3. Minhas S, Kayes O, Hegarty P, et al. What surgical resection margins are required to achieve oncological control in men with primary penile cancer? Br J Urol Int 2005;96:1040-1043.

4. Hakenberg OW, Comperat E, Minhas S, et al. EAU guidelines on penile cancer. Eur Assoc Urol 2016:1-29.

5. Hegarty PK, Kayes O, Freeman A. A prospective study of 100 cases of penile cancer managed according to European Association of Urology guidelines. BJU Int 2006;98:526-531.

6. Omellas AA, Kinchin EW, Nobrega BL. Surgical treatment of invasive squamous cell carcinoma of the penis:Brazilian National Cancer Institute long term experience. J Surg Oncol 2008;97:487-495.
7. Paiva GR, Araujo IBO, Athanazio DA, de Freitas LAR. Penile cancer: impact of age at diagnosis on morphology and prognosis. Int Urol Nephrol 2014:1-5.

8. Prayoga DA, Tranggono U. Evaluasi klinis dan manajemen kanker penis di Rumah Sakit Sardjito, Yogyakarta. Indones J Canc 2016;10:29-34.

9. Tranggono U, Umbas R. Karakteristik dan terapi penderita keganasan penis di RS Ciptomangunkusumo dan RS Kanker Dharmais. Indones J Canc 2008;2:45- 50.

10. Sonpavde G, Pagliaro LC, Buonerba C, et al. Penile cancer: current therapy and future directions. Ann Oncol 2013;24: 179-1189.

11. Slaton JW, Morgenstern N, Levy DA, Set al. Tumor stage, vascular invasion, and the percentage of poorly differentiated cancer:independent prognosticators for inguinal lymph node metastasis in penile squamous cancer. J Urol 2001;165:1138-1142.

12. Dai B, Ye DW, Kong YY, et al. Predicting regional lymph node metastasis in Chinese patients with penile squamous cell carcinoma: the role of histopathological classification, tumor stage and depth of invasion. J Urol 2006;176:1431-1435.

13. Emerson RE, Ulbright TM, Eble JN, et al. Predicting cancer progression in patients with penile squamous cell carcinoma: the importance of depth of invasion and vascular invasion. Mod Pathol 2001;14:963-968.

14. Velazquez EF, Ayala G, Liu H, et al. Histologic grade and perineural invasion are more important than tumor thickness as predictor of nodal metastasis in penile squamous cell carcinoma invading 5 to $10 \mathrm{~mm}$. Am J Surg Pathol 2008;32:974-979.

15. Ramkumar A, Seshadri RA, Narayanaswamy K, Balasubramanian $\mathrm{S}$. Risk factors for lymph node metastasis in clinically node-negative penile cancer patients. Int J Urol 2009;16:383386. 